\title{
Improving the Collaboration between Main Contractors and Subcontractors within Traditional Construction Procurement
}

\author{
Obafemi A. Akintan and Roy Morledge \\ School of Architecture, Design and the Built Environment, Nottingham Trent University, Nottingham NG1 4BU, UK \\ Correspondence should be addressed to Roy Morledge; roy.morledge@ntu.ac.uk
}

Received 11 March 2013; Accepted 11 June 2013

Academic Editor: Edwin Chan

Copyright (C) 2013 O. A. Akintan and R. Morledge. This is an open access article distributed under the Creative Commons Attribution License, which permits unrestricted use, distribution, and reproduction in any medium, provided the original work is properly cited.

\begin{abstract}
The inability of subcontractors/specialist contractors to contribute meaningfully to the construction process under the traditional construction procurement hampers the possibilities of improving value on projects and their integration with the rest of the supply chain. In particular, the main contractors and subcontractors in traditional construction procurement projects pursue their selfinterests to such an extent that collaborative working has been impossible to achieve. In this research, qualitative and quantitative approaches were used to collect data to explore the problems at the root of the main contractor-subcontractor relationship. Intending to derive innovative ideas to reinvent the delivery process of traditional construction procurement, the principles of integrated project delivery (IPD) and the last planner system (LPS) were studied to seek useful ideas that can be employed to improve collaboration between main contractors and subcontractors. A high point of contention is the debate on the managerial competence of subcontractors; nevertheless, hope is expressed at the possibility of improving collaboration between the main contractor and subcontractor within traditional construction procurement work environment.
\end{abstract}

\section{Introduction}

Traditional construction procurement became the main route to procure constructed facilities in the UK soon after the industrial revolution of the nineteenth century $[1,2]$, and to date, it remains the dominant procurement strategy in the UK [3]. It is mostly preferred by one-off clients, who seldom engage in construction. However, in recent times, the use of the traditional construction procurement strategy to procure constructed facilities is falling across the UK [4]. The reason for this decline is because this approach to construction procurement engenders adversarial attitudes [5], and as a result, conflicts and disputes, poor collaboration, a lack of focus on customers' requirements, and failure to satisfy clients' needs have become prevalent in the UK construction industry [6].

Today, construction is so specialised that no one firm can provide all the specialisms; therefore, many smallsized specialist firms (subcontractors) with narrow expertise continue to work to meet the industry's varied and complex demands [7]. This situation increases the demand for interdependence of the specialisms and the operating organisations. According to Kale and Arditi [8], the quality of main contractor-subcontractor relationship affects the main contractors' ability to perform on projects, which inevitably has direct consequences on project outcomes. This implies that as relationships become more harmonious, there is the possibility of improving the effectiveness and performance of the supply chain since project participants are more able to plan and share resources in an atmosphere of collaboration [1]. But Dainty et al. [9] realised that subcontractors have some misgivings about the sincerity of the much talked about collaboration of the supply chain. As such, existing relationships particularly between them and main contractors are riddled with mistrusts and scepticisms. They for instance believe that they are merely used by main contractors to improve their cash flow and survive the volatility of the construction business [10].

This problem is made worse by the contractual structure of the traditional procurement route, which excludes 
subcontractors from the main contract. Morledge [11] argues that the inability of subcontractors and specialist contractors to contribute meaningfully to the construction process under traditional procurement hampers the possibilities of improving value on projects. Specialist contractors and/or subcontractors, as it is well known, play a significant role in the successful delivery of projects, executing between 80 and $90 \%$ of the volume of works on building and housing projects [12-15] To have this important group excluded from collaborative arrangements in the construction process leaves much to be desired.

Owing to their small size and large number, they usually need main contractors to coordinate their operations to provide focus and integration of the varied parts. However, even with main contractors coordinating, focus on selfinterests remains unchanged under traditional construction procurement arrangements, because project delivery processes are still largely disconnected. This leaves room for rivalry amongst project participants, and only the fittest survives [16]. It is the case that, under the traditional approach to construction procurement, contract terms are often so strictly and litigiously applied that little or no consideration is given to sustaining relationships for future business dealings. The desire to seek long term benefits, which comes with collaboration is thus lacking amongst project participants under this approach of project delivery.

In an effort to address these challenges, two industry-led and government-commissioned enquiries were undertaken to look into the activities of the UK construction industry. The outcome of these enquires were the Latham [17] and Egan [18] reports. Amongst others, the reports identified that practices within the UK construction industry were inefficient, fragmented, and ineffective. They also revealed that clients' expectations were not being met and that industry practitioners were making low profits. The reports therefore called for a change in attitudes and for the integration of project delivery processes in the hope that projects' successes are improved and that clients are better served [19].

Fragmentation, according to Briscoe et al. [20], has made the development of a unified approach to project delivery and team continuity between main contractors and key supply chain members difficult over the years. And on traditionally procured projects, it is blamed for client's dissatisfaction with completed projects [5]. To improve performance on traditionally procured projects therefore, the work relationships between main contractors and subcontractors needs to change. Regrettably, however, the use of collaborative tools is nonexistent in traditional procurement [21], and key participants continue to endure and not enjoy their work relationship.

\section{Performance Improvement}

The benefits of integrating the supply chain in order to improve project performance have been established in previous studies $[9,20,22,23]$. It is no surprise therefore that project participants are increasingly realising that sharing knowledge and information is key to project success [23]. A number of these benefits according to Bresnen and Marshall [24] and Constructing Excellence [25, 26] are that collaboration on construction projects

(i) delivers lower building cost for the client and higher profits for the contractor;

(ii) improves the chances of capturing clients' requirements [brief] and their eventual satisfaction;

(iii) recognises and protects the main contractors' profit margin, making them better able to deliver on the quality requirements of projects;

(iv) increases value and predictability of work;

(v) reduces the number and severity of contractual disputes;

(vi) creates an enabling environment for innovation and technical development;

(vii) encourages continuous improvements;

(viii) results in shorter overall project time.

The chances of achieving performance improvements on projects employing collaborative approaches are, in the light of the foregoing, high. Unfortunately, this does not seem to be the case with procurement approaches yet to embrace collaborative principles, as incidences of poor performance are not abating. Bresnen and Marshall [24] however contend that proofs supporting the claimed successes of collaborative projects are doubtful. In support, Briscoe et al. [20] remark that it has been difficult to prove that improved management practices result in improved performance and better integration on construction projects. Somehow, there is no consensus amongst experts on these claimed benefits, at least in a practical sense of events. In spite of this debate, there is a general perception amongst project participants that collaboration is an appropriate way to overcome problems and improve the overall performance of the industry. This is particularly essential for main contractor-subcontractor relationships, which are mostly plagued by conflicts under traditional construction procurement arrangements.

\section{Conflicts in the Main Contractor-Subcontractor Work Relationship}

Contractually, main contractors are responsible for the construction of projects, but they rely on subcontractors and/or specialist contractors and suppliers to execute the works [27]. They do this to reduce their overhead and operating costs, improve efficiency, and achieve a more economic delivery of projects [12], which Hatmoko and Scott [13] believe has helped reduce project delays by $45 \%$. However, to be successful at this, they must develop enduring relationships with key suppliers and specialist contractors [28, 29]. Unfortunately, available information suggests otherwise.

Dainty et al. [9] and Tommelein and Ballard [10] reveal that main contractors in traditional construction procurement are primarily concerned with maximising their profit. They select subcontractors on the basis of lowest price (and 
not on best value) and squeeze them tight on price leaving them struggling to survive. With such attitudes, according to Coase cited in Kale and Arditi [8], they fail to realise that price is not an effective mechanism to sustain business transactions, and in no time things turn sour between them and their work partners [10].

Another negative attitude main contractors exhibit and which inhibits effective collaboration on traditional construction procurement projects is their use of harsh contract terms/clauses in subcontract agreements. Ever so often, clauses to terminate and not to offer damages for delays or the popular "paid when paid" clause [30] have become regular inclusions to standard subcontracts. These clauses are cruelly enforced in such a way that long standing relationships can be terminated the moment there is a failing by the subcontractor [9]. This frustrates subcontractors' attempts to seek compensations even in instances where they are genuinely entitled to them.

Similarly, their tendency to transfer enormous project risks to subcontractors, who are typically small and medium size enterprises (SMEs) with little or no capacity to bear such risks; as well as their reluctance to call on subcontractors' expertise in resolving issues on site [9], all suggest that main contractors are not truly interested in developing cooperative relationships [22]. For these reasons, subcontractors are suspicious of main contractors and remain unconvinced about the genuineness of calls to collaborate.

Main contractors on the other hand, according to Johansen and Porter [31], complain that subcontractors have a habit of bringing inadequate workmen to site, a practice which hampers the works and fuel conflicts. They maintain that in managing their multijob resource pressures from different construction sites, subcontractors adopt the attitude of "the loudest shouter [main contractor] gets the resource today". This often leaves them struggling to meet up work programmes on sites resulting in delays. In defence however, subcontractors insist that they have had to adopt an economic distribution of their workmen, having observed that they are often urged to resume to site only to realise that essential works that ought to have been completed by main contractors or others prior to their invitation have not been completed. The time and resources wasted during these periods of delays usually have financial implications, which they are often not able to claim against thus prompting their cautious approach [9].

It is also the case that main contractors and subcontractors working under the traditional construction procurement arrangement do not plan and develop the project programme together after the project is let. Johansen and Porter [31] opine that this failure to work together unfortunately leads to incorrect and guessed duration of critical activities because sufficient and broad view information was not gathered. This has the potential to cause programmes to fail, resulting in delays on projects.

The blames and counterblames between these key project participants on traditional construction projects are endless. Even on projects where clients buy into the idea of collaboration, main contractors and subcontractors have struggled to drive these principles all the way to project completion. Relationships soon degenerate once it is perceived that potential profits may be eroded, and without recourse to the long standing relationships between them, such relationships break up [9].

The blame culture between main contractors and subcontractors is so severe that it inevitably erodes trust in the relationship. By focusing on their respective self-interests rather than on mutual interests, there have been failings in satisfying clients' needs [25]. It must be said that trust is fundamental in any relationship since people are more likely to work better and freely with those they believe share their values [23]. Where an atmosphere of trust is allowed to thrive in any business dealing, parties will definitely reap the benefits of such interactions [32].

Ankrah et al. [33] unearth a key issue affecting openness and collaboration on construction projects. They noticed that groupings exist within projects or in project organisations in the form of professional stereotypes or allegiances. Members of a particular professional group separate themselves from others, within the same work environment, who they perceive do not share their professional orientations. These behavioural stereotypes and structural (contractual) frameworks are apparent in the main contractor and subcontractor work setting and form barriers between them, thus making effective collaboration difficult [31]. This is why Mignot [34] counsels that project participants have to change their culture stereotypes/ideologies and do away with their professional delineations to be able to implicitly trust one another. Cox et al. [35] are however of the opinion that these problems are not necessarily due to the fact that project participants are "malicious or ignorant", but that they are a consequence of individuals or group of participants pursuing their respective economic self-interests.

The pursuit of self-interests, as it is the case in traditional procurement, creates a mere transactional and not a relational work relationship between the parties. But construction however is actually best delivered by working collaboratively. For this reason, Franz and Leicht [36] stress that adopting relational attitudes will deliver high performing building projects because it creates a collaborative system.

Having a more equitable distribution of project risks is another way to engender trust between main contractors and subcontractors in traditional construction procurement, because as Kadefors [32] affirms, fairness is fundamental to trust. By sharing risks, relational atmospheres in which parties see projects as a "collective enterprises" are created, thus strengthening the chances of improving project outcomes.

Dainty et al. [9] also identify that there is poor level of information sharing between main contractors and subcontractors. They reveal subcontractors' unhappiness with main contractors' insensitivity to their need for prompt and correct information. Therefore, expectedly, subcontractors are worried that the traditional approach to construction procurement hinders effective knowledge exchange amongst participating companies. A system that ensures a prompt and sustained sharing of information must thus be developed. Main contractors and subcontractors must realise that if information flow is affected or knowledge sharing is hindered [23], it will eventually affect the level of trust between them. 
Kadefors [32] maintains that there are occasions when project participants jointly resolve problems that arise in the course of the works, but these are often spontaneous and unplanned. The attempts centre primarily on finding compromises or are simply exchange of services. In reality, the resolution processes fall short of developing and establishing a continuous search for improvements and innovative resolution of problems. An established system to seek continuous improvements will help contracting organisations develop an organisational capability that is informed, experienced, and organised [34], which may further help to achieve lasting solutions, and lessons gained can be transferred unto future interactions [projects].

\section{Adopting Relational Approaches in Traditional Construction Procurement}

One of the very first things supply chain collaboration attempts to achieve is to eliminate [process] waste. Vrijhoef and Koskela [37] suggest that making wastes and problems visible early during the construction process and identifying their root help to resolve problems that may develop later. This process of bringing potential issues of conflicts forward for discussion and the development of alternative strategies should involve all key players in the supply chain, because, most often, construction problems have a knock-on effect across the chain, thus necessitating group resolutions.

To date, four ingrained practices have made it difficult to implement collaborative principles under traditional construction procurement strategies [16]. They are that the strategy

(i) inhibits contribution of valuable ideas,

(ii) restricts risk sharing possibilities,

(iii) hampers effective project coordination,

(iv) creates rivalry.

An efficient way to resolve these problems [38] entails thinking through the interdependency of tasks (the work flow) to eliminate wastes, delays, and extra cost, which is best achieved through the collaborative involvement of all supply chain members.

To realise performance improvements on traditionally procured projects therefore, there is a need for less emphasis on the use of entrenched control mechanisms (i.e., price, process, and contract controls), to relationship building, and a general commitment to satisfy clients' needs. Two of such relational approaches are briefly discussed in the following to highlight inherent principles within that could be imported unto traditional construction procurement to improve main contractor-subcontractor relationships.

4.1. Integrated Project Delivery (IPD) Approach. Smith et al. [39] describe IPD as “... a new set of relationships in a project.” As argued earlier, projects are more likely to succeed in relational relationships than in mere transactional ones. The use of IPD principles which have helped to deliver high performing projects by creating a collaborative system can serve to address the relational problems in traditional construction procurement. IPD administered projects are easy to manage because all project participants (the IPD team) sign up to a single principal contract with the client.

Smith et al. [39] however admit that the administration of such multiparty system requires considerable experienced clients and contractors' involvement. The approach nonetheless ensures that all members are responsible for all provisions of the contract and that risks and profits are truly shared [16], which are problems that sit at the heart of the adversarial nature of traditional procurement. This will make main contractors and subcontractors and indeed every other project participant work as friends and look out for the interest of the client, because they jointly and individually commit themselves to each other to perform all the terms, conditions, and requirements of the principal contract.

Highlighting the enormous commitment required for the successful implementation of IPD ideologies, Mignot [34] maintains that there are challenges with administering projects under IPD arrangements. He reports that to have a successful alliance management team on a project, the subgroups which make up the alliance must have collaborative abilities; do away with their stereotypes and organisational or professional delineations; create a management structure that is informed, experienced, and organized; and implicitly trust one another. These requirements may well be daunting to achieve across the project subgroups.

4.2. Last Planner System Approach. Another approach from which principles can be learned to manage challenges between main contractors and subcontractors within the traditional construction procurement strategy is the last planner system (LPS). Although LPS centres primarily on project programming and planning, it can yet bring collaborative and relational commercial terms into one-off-project-based production [40]. This view is reinforced by Glenn Ballard's belief cited in Mossman [40] that LPS works in all situations that require coordination between humans.

LPS is a production tool developed by the Lean Construction Institute to improve planning on construction projects [31]. Its essential objective is to build trust amongst project participants in five key ways which Mossman [40] refer to as conversations. They include

(i) collective pull-based planning;

(ii) "make ready";

(iii) collaborative production evaluation and planning (PEP);

(iv) production management;

(v) measurement, learning, and continual improvement.

Operating within the framework of these conversations will ensure processes in the planning, development, and execution stages of projects are jointly developed by all key members of the project. But, as with the use of IPD, a concern with implementing LPS, as Johansen and Porter [31] caution, is that of the contractual structures of the projects where LPS is to be applied and the behavioural stereotypes 
to its implementors. So, is there a chance of reinventing the traditional construction procurement strategy? This is the key question this research sought to answer.

\section{Problem Statement}

The focus of previous studies has been on collaboration at the precontract stage of projects or collaboration under partnering arrangements. None has explored the possibilities of employing collaborative tools within the traditional construction procurement supply chain with the aim of improving the main contractor-subcontractor work relationship. Following RICS's [3] submission that traditional procurement is the dominant approach in the UK and that it sits at the heart of the industry's problems [20], the possibility for achieving improved performance in traditional procurement needs to be examined. With these issues in mind, this paper sought to examine the working relationship between main contractors and subcontractors in an effort to improve collaboration in the traditional construction procurement supply chain. The focus on subcontractors is necessary because of the vital role they play in actualising projects and the subordinate position they operate within this procurement structure.

Essentially, this research investigated the possibilities of employing collaborative tools within traditional construction procurement by exploring the suitability of the key principles of relational building procurement approaches that is, integrated project development (IPD) and the last planner system (LPS) in traditional construction procurement environments to improve the main contractor-subcontractor work relationship.

\section{Methodology and Methods}

In the first instance, the relational problems between main contractors and subcontractors were examined, and the reasons for these problems were then unearthed through field studies. The research combined the use of quantitative and qualitative approaches in which questionnaires and interviews were used to obtain relevant information about the subject from professional construction practitioners. This helped to identify the barriers to effective main contractors and subcontractors' collaboration.

Questionnaires have been successfully used in previous similar researches. As Bryman [41] states, although this method of data collection suffers from poor response rate, it nonetheless allows views from a wide range of credible participants to be obtained. Interviews on the other hand are great at gathering opinions which questionnaires are unable to reveal. In deploying this tool (interviews), the discussions with the interviewees were analysed [23] to establish common themes.

118 questionnaires were distributed electronically between main contractors, subcontractors/specialist contractors, consultants, and construction professionals working in client organisations, and of which 37 which met a preset criterion were accepted for analyses. Envisaging a poor rate of response due to the current low activity level of the industry,

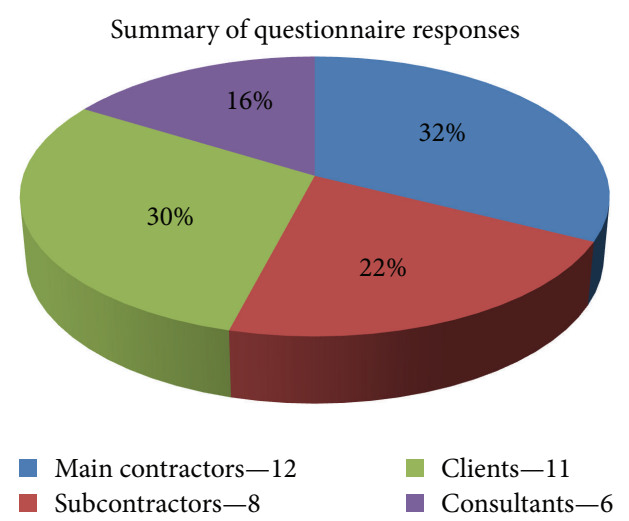

FIGURE 1: Summary of questionnaire responses.

and in an attempt to ensure the credibility of the results, the questionnaires were only directed to professionals with over five years' experience. This criterion was clearly stated in the solicitation for information notice of the survey. It cannot be ascertained if this requirement affected the rate of response, but the desire to receive credible feedbacks was overriding. This poor responses rate of $31.36 \%$ notwithstanding is within the range of responses from construction management researches like those by Chan et al. [42] and Oladapo [43]. Also, three semistructured interviews were conducted with senior construction managers to obtain more in-depth information. Those interviewed had previously participated in the questionnaire survey and had worked on projects where collaborative practices were employed.

In analysing the results, responses were sorted into identifiable categories: main contractors, specialist contractors, clients, and consultants. Then, multiplying the frequency of responses received for each question against weighted rankings, ranging from 1 (strongly disagree) to 5 (strongly agree), scored by the respondents, the variable with the highest value was chosen to represent the most popular option. Regarding the interviews, recordings were first transcribed, and a content analysis to identify common themes was then undertaken. The results of the research are presented below, and suggestions on how improved collaboration can be achieved in the traditional procurement process are offered.

\section{Results and Discussions}

A breakdown of the 37 returned questionnaires presented in Figure 1 shows that they were answered by 12 main contractors, 8 specialist contractors (subcontractors), 11 client organisations professionals, and 6 construction consultants.

As shown in Figure 2, there is a general lack of enthusiasm about the idea of adopting collaborative principles within traditional construction procurement environment. $65 \%$ of those surveyed strongly disagree, disagree or are completely indifferent to the use of collaborative tools within traditional procurement.

Analysing the previous result further (see Table 1) reveals that main contractors are the most sceptical within the group of participants surveyed about the chances of a successful 
How well do respondents believe it is easy to employ collaborative tools in traditional procurement?

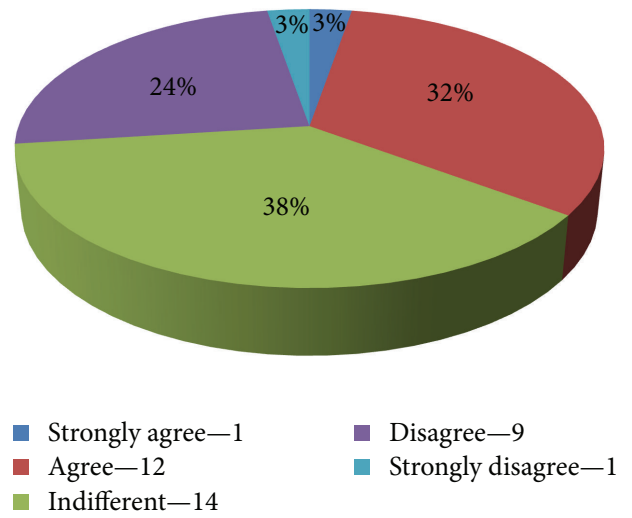

Figure 2: Belief in the possibility of employing collaborative tools in traditional procurement.

use of collaborative principles in traditional construction procurement environments, with $75 \%$ of them showing a lack of belief in the idea.

This result however corroborates Eriksson et al. [22] finding that main contractors are not interested in developing cooperative relationships with subcontractors, at least on one-off projects.

However, clients show a desire for collaboration to take root in this age-long procurement practice. This demand thus places a burden on construction professionals to yet seek ways of achieving this all important client desire.

Construction managers interviewed expressed similar doubts about the possibilities of employing collaborative principles within traditional construction procurement arrangements. They affirm that " $\ldots$ it would be very difficult to use because people [main contractors] are often looking for someone [subcontractor] to take the risks so that they can maintain their fixed price [profit level]", as "... risks are literally sent down to subcontractors". They further maintain that "this tendency to transfer risks down the supply chain makes the possibility to collaborate under traditional procurement difficult". A fact also argued by the interviewees is that "... collaboration had worked in framework agreements because they [the collaborating companies] will all be longterm beneficiaries of that arrangement, but talking of one-off projects, it's very difficult to collaborate because you wouldn't want to share a potential loss?"

This information indicates that the risk management approach adopted on projects influences the decision to collaborate. For this reason, it is doubtful if subcontractors will collaborate under traditional procurement arrangements knowing that main contractors will transfer almost all of the project risks to them. This disclosure agrees with Bresnen and Marshall's assertion cited in Eriksson et al. [6] that appropriate project risk management strategy [help] integrates the supply chain.

Amongst a range of factors investigated (see Figure 3), the lack of trust ranked highest as the main barrier to integration on construction projects, especially on those procured
Factors hindering subcontractors-main contractors' collaboration under traditional construction procurement

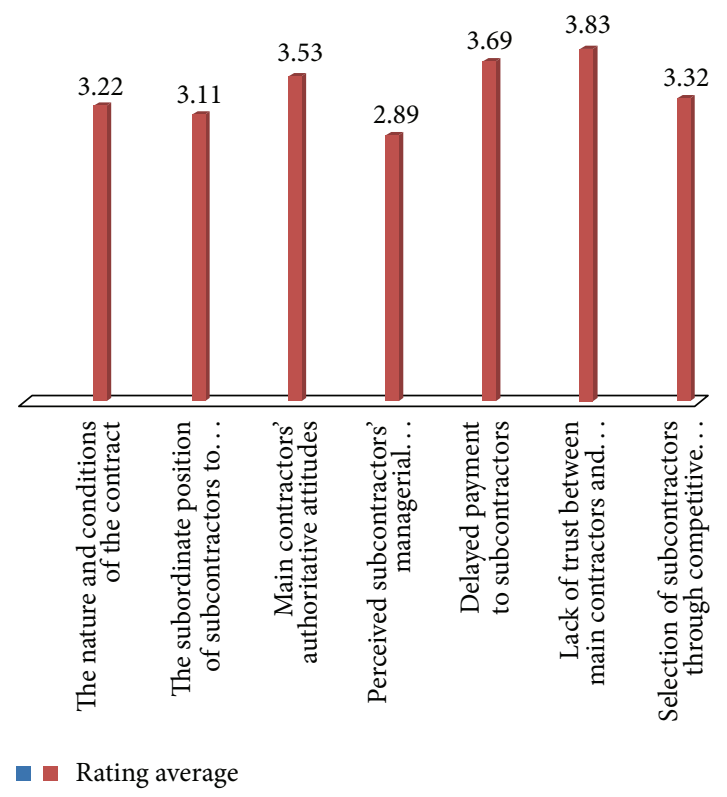

FIGURE 3: Factors hindering effective subcontractors-main contractors' collaboration under traditional construction procurement. Source: Authors' SurveyMonkey, 2012.

under traditional construction procurements arrangements. This is followed by the problem of delayed payments to subcontractors, while the authoritarian practices main contractors employ against subcontractors come third amongst the ranked factors. Although researches by Dainty et al., [9] and Thomas and Flynn [30] have similarly identified some of these factors, they did not unearth the reason for the breakdown of trust. This research establishes a link between the lack of trust and the problem of delayed payments to subcontractors by main contractors. In the view of one of the interviewees, it is because "... prime subcontractors don't get paid in a timely manner" that trust is eroded.

Unfortunately, efforts at getting main contractors to deal fairly with their chain of subcontractors have mainly been unsuccessful. Irrespective of the fact that standard contracts stipulate periods within which subcontractor should get paid, those interviewed were unanimous in their opinion that such specified periods are repeatedly ignored, with subcontractors often stretched to the limits before getting paid. A lot therefore needs to be done to build trust in construction businesses because as Ouchi cited by McDermott et al. [23] found, there is a direct relationship between the level of trust and the costs of transactions, which in turn has effects on clients.

The findings of this research similarly indicate that there is a perception amongst some main contractors that subcontractors are not managerially competent. Although this view is not seen to be a significant contributor to the breakdown in relationship, as it is scored the least (Figure 3) amongst the list of suggested hindrances to effective main contractor-subcontractor collaboration, further analyses of 
TABLE 1: Breakdown of responses to question 2-It is easy to employ collaborative tools in traditional procurement.

\begin{tabular}{|c|c|c|c|c|c|c|}
\hline Variables (level of agreement) & $\begin{array}{c}\text { Weighting }(1= \\
\text { strongly disagree, } 5= \\
\text { strongly agree })\end{array}$ & $\begin{array}{c}\text { Main } \\
\text { contractors }\end{array}$ & Clients & $\begin{array}{c}\text { Specialist } \\
\text { contractors/subcontractors }\end{array}$ & Consultancy & Total score \\
\hline Strongly disagree (frequency) & 1 & & & 1 & & \\
\hline Score & & 0 & 0 & 1 & 0 & 1 \\
\hline Disagree (frequency) & 2 & 4 & 2 & 2 & 4 & \\
\hline Score & & 8 & 4 & 4 & 8 & 24 \\
\hline Indifferent (frequency) & 3 & 5 & 5 & 3 & 1 & \\
\hline Score & & 15 & 15 & 9 & 3 & 42 \\
\hline Agree (frequency) & 4 & 2 & 4 & 2 & 1 & \\
\hline Score & & 8 & 16 & 8 & 4 & 36 \\
\hline Strongly agree (frequency) & 5 & 1 & & 0 & & \\
\hline Score & & 5 & 0 & 0 & 0 & 5 \\
\hline
\end{tabular}

Score $=$ weighting $\times$ frequency.

TABLE 2: Comparison of scores given by main contractors and subcontractors to the perceived managerial incompetence of subcontractors as being a hindrance to their collaboration.

\begin{tabular}{|c|c|c|c|c|c|c|}
\hline \multirow{2}{*}{ Respondents } & \multirow{2}{*}{$\begin{array}{l}\text { Number of } \\
\text { responses }\end{array}$} & \multicolumn{5}{|c|}{ Perceived subcontractors' managerial incompetence rating $(1=$ least important, $5=$ most important $)$} \\
\hline & & 1 & 2 & 3 & 4 & 5 \\
\hline Main contractors & 12 & 1 & 0 & $9^{*}$ & $16^{*}$ & $20^{*}$ \\
\hline Subcontractors & 8 & $2^{\#}$ & $8^{\#}$ & $3^{\#}$ & 0 & 5 \\
\hline Consultants & 6 & 0 & 6 & 9 & 0 & 0 \\
\hline Clients & 11 & 0 & 10 & 12 & 8 & 0 \\
\hline
\end{tabular}

* Upper range score given by main contractors.

"\# Lower range score given by subcontractors.

the result, which is presented in Table 2, show contrasting main contractors and subcontractors views. The analyses reveal that main contractors' respondents ranked the fact that subcontractors' managerial incompetence is a hindrance to effective collaboration at the upper end of the ranking scale. This is perhaps an indication that they doubt subcontractors' ability to manage projects. Understandably, subcontractors' rankings were within the lower end of the scale, suggesting an assertion of their managerial competence. It comes as no surprise therefore that subcontractors complain that main contractors are often reluctant to draw on their expertise when problems occur on site [9].

There is a strong indication from the foregoing that this main contractors' subtle lack of confidence in subcontractors' managerial ability leads them to unnecessarily interfere in subcontractors' operations on site, which has a potential of resulting in conflicts. One such interference an interviewee argues is the many control mechanisms, such as the multilevel approval system, which main contractors have introduced and to which subcontractors must comply. Defending this practice, another interviewee maintains that such controls exist to keep with quality control and assurance requirements. "It is important to ensure subcontractors undergo checks at every stage of the project before they are cleared to proceed", he affirms. This statement only serves to confirm complaints that main contractors in the guise of controlling the project under traditional construction procurement assert authority in such a way that they undermine subcontractors' ability to function effectively and maximise their profits [9].

While the need to keep up to quality assurance requirements is not contested, the use of multilevel approvals (signoffs) to meet standards has unfortunately become the main focus on most sites and fast resulting in an excess of procedures and practices, argues another interviewee. This procedural waste may very well have been avoided or at least substantially reduced with better collaboration between main contractors and subcontractors built on a strong confidence in not just the technical competence of subcontractors, but also on their managerial competence.

The lack of confidence between main contractors and subcontractors has turned out to affect the delivery processes of traditionally procured projects in a number of ways. Since the use of common processes is a fundamental collaborative principle, its absence in any project delivery process can only mean chaos. Presently, on traditional construction procurement projects, there is no joint decision process between main contractors and subcontractors. As depicted in Figure 4, as much as $46 \%$ of project participants indicated that they were only occasionally part of the decision making processes on construction sites.

On further analyses of this result shown in Table 3 , it is immediately apparent that the outcry of none inclusion 
TABLE 3: How often project participants take decisions jointly.

\begin{tabular}{|c|c|c|c|c|c|c|}
\hline Variables (level of occurrence) & $\begin{array}{c}\text { Weighting }(1= \\
\text { strongly disagree, } 5= \\
\text { strongly agree })\end{array}$ & $\begin{array}{l}\text { Main } \\
\text { contractors }\end{array}$ & Clients & $\begin{array}{c}\text { Specialist } \\
\text { contractors/subcontractors }\end{array}$ & Consultancy & Total score \\
\hline Never (frequency) & 1 & & & & & \\
\hline Score & & 0 & 0 & 0 & 0 & $\mathbf{0}$ \\
\hline Occasionally (frequency) & 2 & 6 & 4 & 5 & 2 & \\
\hline Score & & 12 & 8 & 10 & 4 & 34 \\
\hline Do not know (frequency) & 3 & 4 & & & & \\
\hline Score & & 12 & 0 & 0 & 0 & 12 \\
\hline Often (frequency) & 4 & & 5 & 3 & 2 & \\
\hline Score & & 0 & 20 & 12 & 8 & 40 \\
\hline Very often (frequency) & 5 & 2 & 2 & & 2 & \\
\hline Score & & 10 & 10 & 0 & 10 & 30 \\
\hline
\end{tabular}

Score $=$ weighting $\times$ frequency.

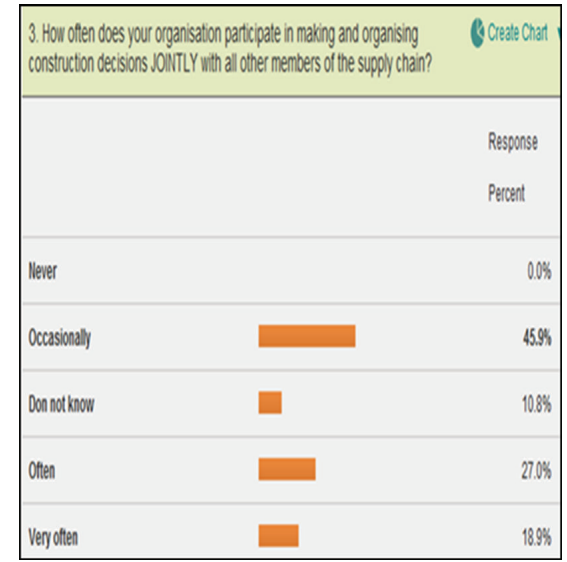

Figure 4: Frequency of involvement in decision making. Source: Authors' SurveyMonkey, 2012.

in decision making processes is a complain predominant amongst subcontractors. Although some main contractors did indicate that they are also left out of decision making processes, this is however doubtful because it is expected that they control the flow of information. The disconnect in sharing information and in the management of construction processes, especially under traditionally procured projects which this investigation reveals, is disturbing regardless of who is making the complaint. This finding contradicts McDermott et al. [23] conclusion that project participants are increasingly realising the benefits of information sharing. An interviewee sheds light on the reason for the disconnect putting it down to adherence to stereotypes. He argues that "... it's just a culture thing ... for instance it's just QSs' [quantity surveyors] looking at the upfront cost and seeing it [subcontractors' inputs] as a cost rather than as something to add value ...". It also emerged that consultants do not often follow subcontractors' suggestions for fear of the consequence, should problems arise, and not wanting to be held professionally negligent.

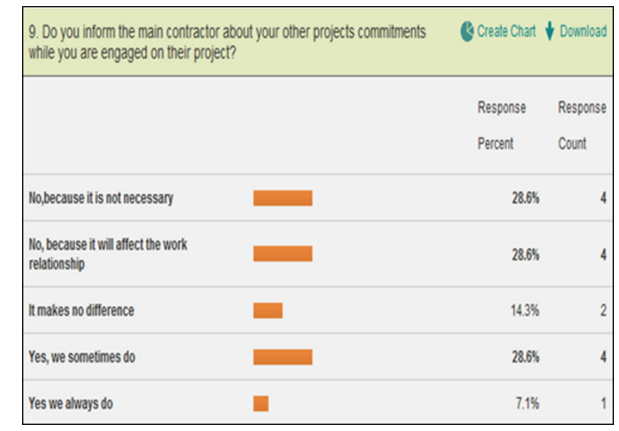

FIgURE 5: Informing main contractors about other project commitments-subcontractors' view. Source: Authors' SurveyMonkey, 2012.

Other lines of enquiry reveal that not only are subcontractors prevented from decision making processes, but they are more or less also forced to comply. A significant number of main contractors indicate that they allow subcontractors little or no flexibility to debate or challenge their decisions.

The results in Figure 5 show that subcontractors are not transparent in their dealings with main contractors. $47 \%$ of them admit that they do not inform main contractors of their other projects' commitments because they either believe it is unnecessary or because they think it will affect the [existing] work relationship. This practice demonstrates a lack of transparency and does not also encourage collaboration, which further breaks down trust.

Partners in a work relationship, who are desirous of collaborating, must be open about all of their other work commitments. Concealing such important information has the potential of affecting resource planning and allocation on current projects, thereby hampering work progress.

Perhaps a factor which frustrates attempts at employing collaborative strategies within traditional construction procurement in spite of best intentions is the contract of engagement. When main contractors were asked for the reasons for the negative and unfriendly practices that run under 
this procurement route, they were definite that the nature and conditions of contracts are a key influence. Indeed, the Institution of Civil Engineers (ICE) and the Joint Contracts Tribunal (JCT) standard forms are notorious for being adversarial, whereas the New Engineering Contract Engineering and Construction Contract (NEC ECC) seeks to have more power swing relationships amongst stakeholders. Confirming this, an interviewee expresses that it is not uncommon to see main contractors treat the same subcontractors differently on the different projects they are both engaged on as it is the contract that determines the flow of things.

This research set out to investigate the possibility of employing the collaborative principles of the Integrated Project Delivery (IPD) approach and the Last Planner System (LPS) within traditional construction procurement. But, with the majority of respondents unconvinced about the application of collaborative principles within traditional construction procurement and their quick reference to the nature of contract used under this form of procurement, there is little hope of introducing a single standard form of contract to bind all participants to the client, as used in IPD. However, improvements using the LPS to break down barriers in the main contractor-subcontractor relationship are achievable. LPS's recognition of construction as a social process and its use in managing relationships makes it a viable tool to reinventing the traditional construction procurement system. Respondents are in agreement on the need for collective planning and production processes, and so useful lessons from LPS, which addresses these issues, can be applied to traditional construction procurement arrangements.

The inability of the existing traditional construction procurement contractual structure to encourage collaboration between main contractors and subcontractors is clear. Coupled with a range of main contractors' negative attitudes towards subcontractors, the possibility of achieving true collaboration under this construction procurement approach will still take some time to achieve. Nevertheless, to foreclose any possibility for improved collaboration under traditional construction procurement undermines the goal to improve performances in the UK construction industry.

\section{Conclusions}

This paper examined some of the relational problems between main contractors and subcontractors, and the practices engendering them have been identified. It established that there is a general lack of enthusiasm between main contractors and subcontractors to adopt collaborative processes within traditional construction procurement projects, which is due largely to the mistrust between them. It revealed on the other hand that construction clients are willing to see collaborative processes adopted, since the majority of them still prefer this route (traditional procurement) to procure their constructed facilities.

Amongst other things, the main reasons for the breakdown of trust between main contractors and subcontractors on traditional construction procurement are the issues of delayed payments to subcontractors, disruption to work their plan, their exclusion from decision making processes, and the inclusion of harsh contract terms in subcontract agreements by main contractors. Perhaps the most controversial debate is that which centres on the managerial competence of subcontractors. These, as well as main contractors' tendencies to transfer enormous project risks to subcontractors, make a truly relational relationship under traditional construction procurement a wish, rather than a reality. Majority of the research respondents are thus sceptical about the possibility of employing collaborative principles on traditional construction procurement projects. The research found that most of the problems identified above emanate because of the standard form of contract employed in traditional construction procurement.

Irrespective of these obstacles, particularly regarding the form of contract in use, this research advocates that these challenges are not insurmountable and there is yet a possibility for participants [main contractors and subcontracts in particular] to collaborate and overcome their relational problems under traditional construction procurement projects. Looking to more relational procurement strategies, that is, integrated project delivery (IPD) and the last planner system (LPS), proved that collaborations are achievable. An immediate challenge for the introduction of IPD principles in traditional construction procurement is the impracticability of using a single contract to bind all the project participants to the client because of the structure of the procurement strategy. The possibility of improving relationships within the procurement strategy, using the ideologies of LPS, remains very much achievable.

This offers some hope that the UK's traditional construction procurement approach to project delivery can indeed be reinvented. LPS's adaptability to any standard form and its applicability to address waste, delays, and lack of coordination in construction processes means it will not only breakdown adversarial tendencies known with traditional procurement, but will ensure commitments on projects, thereby allowing collaborative programming and production planning decisions to be more easily made. This claim however needs further practical verification. A suggestion for future research should seek the practical application of the Last Planner System's five conversations within a traditional construction procurement environment to ascertain the veracity of the claim reached in this research that its application within traditional construction procurement will improve collaboration between main contractors and subcontractors.

Finally, true collaboration within traditional construction procurement supply chain is only achievable if parties commit to the ideals of collaboration. They must seek not only to transact but to relate in order to build trust. Main contractors and subcontractors in particular must be ready to place some of their profits at risk, rather than seek to reap rewards at each other's expense.

\section{References}

[1] S. Rowlinson and P. McDermott, Procurement Systems: A Guide to Best practice in Construction, E \& EN Spon, London, UK, 1999. 
[2] M. Saad, M. Jones, and P. James, "A review of the progress towards the adoption of supply chain management (SCM) relationships in construction," European Journal of Purchasing and Supply Management, vol. 8, no. 3, pp. 173-183, 2002.

[3] RICS, Survey of Building Contracts in Use During 2007, The Royal Institution of Chartered Surveyors, London, UK, 2007.

[4] CIOB [Chartered Institute of Building], Procurement in the Construction Industry, CIOB, West Berkshire, UK, 2010.

[5] X. Xue, Y. Wang, Q. Shen, and X. Yu, "Coordination mechanisms for construction supply chain management in the Internet environment," International Journal of Project Management, vol. 25, no. 2, pp. 150-157, 2007.

[6] P. E. Eriksson, T. Nilsson, and B. Atkin, "Client perceptions of barriers to partnering," Engineering, Construction and Architectural Management, vol. 15, no. 6, pp. 527-539, 2008.

[7] J. Bennett and D. Ferry, "Specialist Contractors: a review of issues raised by their new role in building," Construction Management and Economics, vol. 22, no. 5, pp. 521-532, 1990.

[8] S. Kale and D. Arditi, "General contractors' relationships with subcontractors: a strategic asset," Construction Management and Economics, vol. 19, no. 5, pp. 541-549, 2001.

[9] A. R. J. Dainty, G. H. Briscoe, and S. J. Millett, "Subcontractor perspectives on supply chain alliances," Construction Management and Economics, vol. 19, no. 8, pp. 841-848, 2001.

[10] D. Tommelein and G. Ballard, "Coordinating specialists," Journal of Construction Engineering and Management (ASEC), pp. 1-11, 1998.

[11] R. Morledge, "A review of the value of the main contractor," in Proceedings of the Construction and Building Research Conference of the Royal Institution of Chartered Surveyors (COBRA '08), London, UK, September 2008.

[12] D. Arditi and R. Chotibhongs, "Issues in subcontracting practice," Journal of Construction Engineering and Management, vol. 131, no. 8, pp. 866-876, 2005.

[13] J. U. D. Hatmoko and S. Scott, "Simulating the impact of supply chain management practice on the performance of medium-sized building projects," Construction Management and Economics, vol. 28, no. 1, pp. 35-49, 2010.

[14] K. D. Hampson and T. Kwok, "Strategic alliances in building construction: a Tender evaluation tool for the public sector," Journal of Construction Procurement, vol. 3, no. 1, pp. 28-41, 1997.

[15] J. Hinze and A. Tracey, "Contractor-subcontractor relationship: the subcontractor's view," Journal of Construction Engineering and Management, vol. 120, no. 2, pp. 274-287, 1994.

[16] O. Matthews and G. A. Howell, "Integrated project delivery an example of relational contracting," Lean Construction Journal, vol. 2, no. 1, pp. 46-61, 2005.

[17] S. M. Latham, Constructing the Team: Final Report of the Government/Industry Review of Procurement and Contractual Arrangements in the UK Construction Industry, HMSO, London, UK, 1994.

[18] S. J. Egan, Rethinking Construction: The Report of the Construction Task Force on the Scope for Improving the Quality and Efficiency of UK Construction, HMSO, London, UK, 1998.

[19] A. Wolstenholme, Never Waste a Good Crisis: A Review of Progress Since Rethinking Construction and Thoughts for Our Future, Constructing Excellence, London, UK, 2009.

[20] G. Briscoe, A. R. J. Dainty, and S. Millett, "Construction supply chain partnerships: skills, knowledge and attitudinal requirements," European Journal of Purchasing and Supply Management, vol. 7, no. 4, pp. 243-255, 2001.
[21] P. E. Eriksson and A. Laan, "Procurement effects on trust and control in client-contractor relationships," Engineering, Construction and Architectural Management, vol. 14, no. 4, pp. 387-399, 2007.

[22] P. E. Eriksson, M. Dickinson, and M. M. A. Khalfan, "The influence of partnering and procurement on subcontractor involvement and innovation," Facilities, vol. 25, no. 5-6, pp. 203214, 2007.

[23] P. McDermott, M. M. A. Khalfan, and W. Swan, "An exploration of the relationship between trust and collaborative working in the construction sector," Construction Information Quarterly, vol. 6, no. 4, pp. 140-146, 2004.

[24] M. Bresnen and N. Marshall, "Partnering in construction: a critical review of issues, problems and dilemmas," Construction Management and Economics, vol. 18, no. 2, pp. 229-237, 2000.

[25] Constructing Excellence, "Partnering in Practice. Construction Excellence," 2004, http://www.constructingexcellence.org.uk/download.jsp?url=\%2Fpdf\%2Fcase_studies $\% 2$ Fwestern_challenge.pdf.

[26] Constructing Excellence, "Supply Chain Partnering. Construction Excellence," 2004, http://www.constructingexcellence .org.uk/download.jsp?url=/pdf/case_studies/taylor_wood-row_ sap.pdf.

[27] L. Clarke and G. Herrmann, "Cost vs. production: disparities in social housing construction in Britain and Germany," Construction Management and Economics, vol. 22, no. 5, pp. 521-532, 2004.

[28] J. Hook, "Industry issues. PWC," 2012, http://www.pwc.co .uk/engineering-construction/issues/index.jhtml.

[29] L. S. Pheng and C. J. Chuan, "Just-in-time management in precast concrete construction: a survey of the readiness of main contractors in Singapore," Integrated Manufacturing Systems, vol. 12, no. 6-7, pp. 416-429, 2001.

[30] H. R. Thomas and C. J. Flynn, "Fundamental principles of subcontractor management," Practice Periodical on Structural Design and Construction, vol. 16, no. 3, pp. 106-111, 2011.

[31] E. Johansen and G. Porter, "An experience of introducing last planner into a UK construction project," in Proceedings of the 10th Annual Conference of the International Group for Lean Construction, International Group for Lean Construction, Virginia, Va, USA, July 2003.

[32] A. Kadefors, "Trust in project relationships-inside the black box," International Journal of Project Management, vol. 22, no. 3, pp. 175-182, 2004.

[33] N. A. Ankrah, D. Proverbs, and Y. Debrah, "Factors influencing the culture of a construction project organisation: an empirical investigation," Engineering, Construction and Architectural Management, vol. 16, no. 1, pp. 26-47, 2009.

[34] A. Mignot, "Alliancing benefits and challenges in infrastructure projects. Project Manager," 2011, http://projectmanager.com .au/managing/cost/alliancing-benefits-and-challenges-in-infrastructure-projects $/ 3 /$.

[35] A. Cox, P. Ireland, and M. Townsend, Managing in Construction Supply Chains and Markets, Thomas Telford, London, UK, 2006.

[36] B. Franz and R. M. Leicht, "Initiating IPD Concepts on Campus Facilities with a "Collaboration Addendum". Construction Research Congress 2012 ASCE," 2012, http://rebar .ecn.purdue.edu/crc2012/papers/pdfs/-81.pdf.

[37] R. Vrijhoef and L. Koskela, "Roles of Supply Chain Management in Construction. Proceedings of the Seventh Annual Conference ofthe International Group for Lean Construc- 
tion (IGLC-7) Berkeley, Calif, USA," 1999, http://www.ce.berkeley.edu/ tommelein/IGLC-7/PDF/Vrijhoef\&Koskela.pdf.

[38] G. Ballard, "Improving Work Flow Reliability. Proceedings of the Seventh Annual Conference of the International Group for Lean Construction (IGLC-7) Berkeley, Calif, USA," 1999, http:// www.ce.berkeley.edu/ tommelein/IGLC-7/PDF/Ballard.pdf.

[39] R. E. Smith, A. Mossman, and S. Emmitt, "Lean and integrated project delivery. Special Issue," Lean Construction Journal, pp. $1-16,2011$.

[40] A. Mossman, "Last Planner: collaborative conversations forpredictable design \& constructiondelivery. The Change Business Ltd," 2012, http://nrl.northumbria.ac.uk/2631/1/Johansen\% 20E\%20and\%20Porter\%20G\%20An\%20experience\%20of\%20 introducing\%20last\%20planner\%20into\%20a\%20UK\%20construction\%20project.pdf.

[41] A. Bryman, Social Research Methods, Oxford University Press, New York, NY, USA, 3rd edition, 2008.

[42] A. P. C. Chan, D. W. M. Chan, and K. S. K. Ho, "Partnering in construction: critical study of problems for implementation," Journal of Management in Engineering, vol. 19, no. 3, pp. 126-135, 2003.

[43] A. A. Oladapo, "An investigation into the use of ICT in the Nigerian construction industry," Electronic Journal of Information Technology in Construction, vol. 12, pp. 261-277, 2007. 

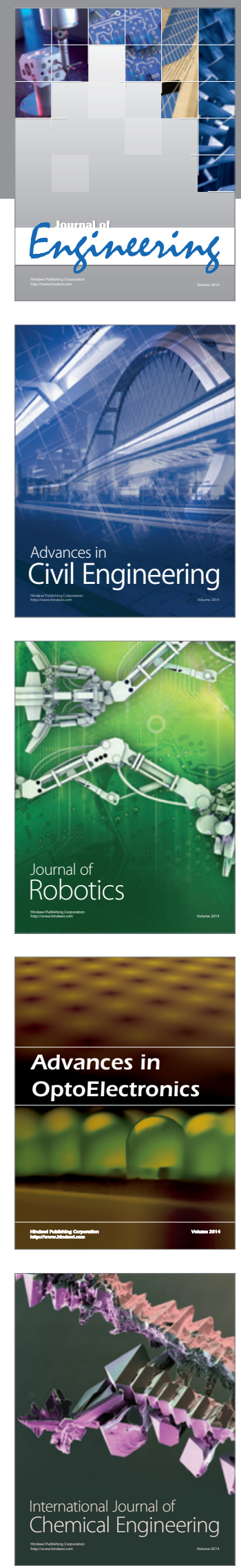

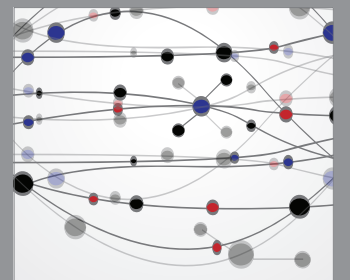

The Scientific World Journal
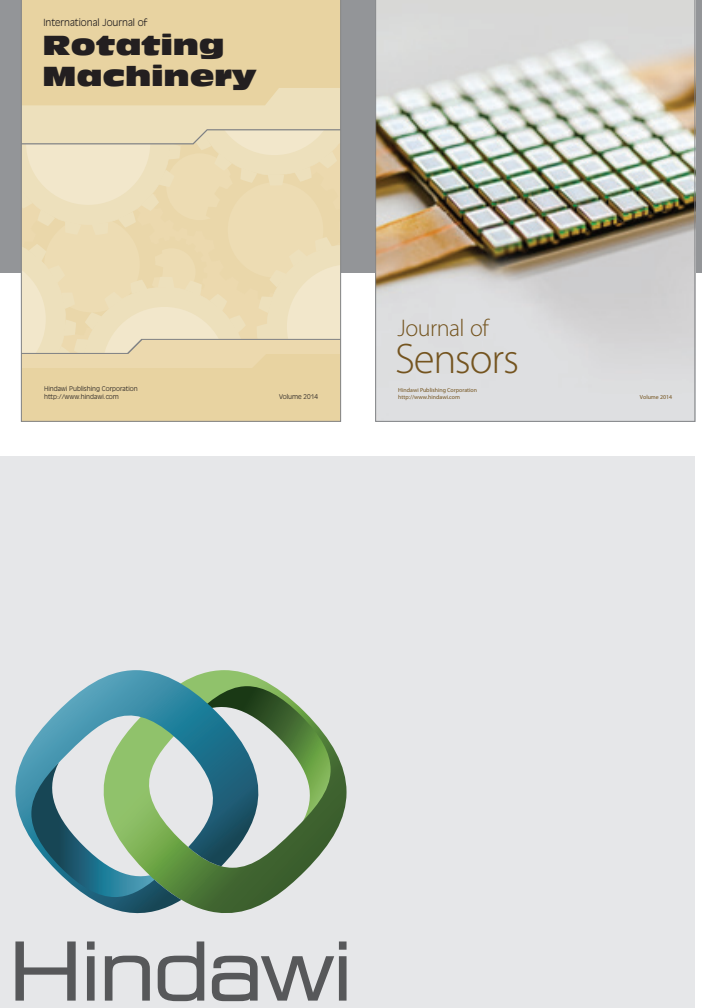

Submit your manuscripts at http://www.hindawi.com
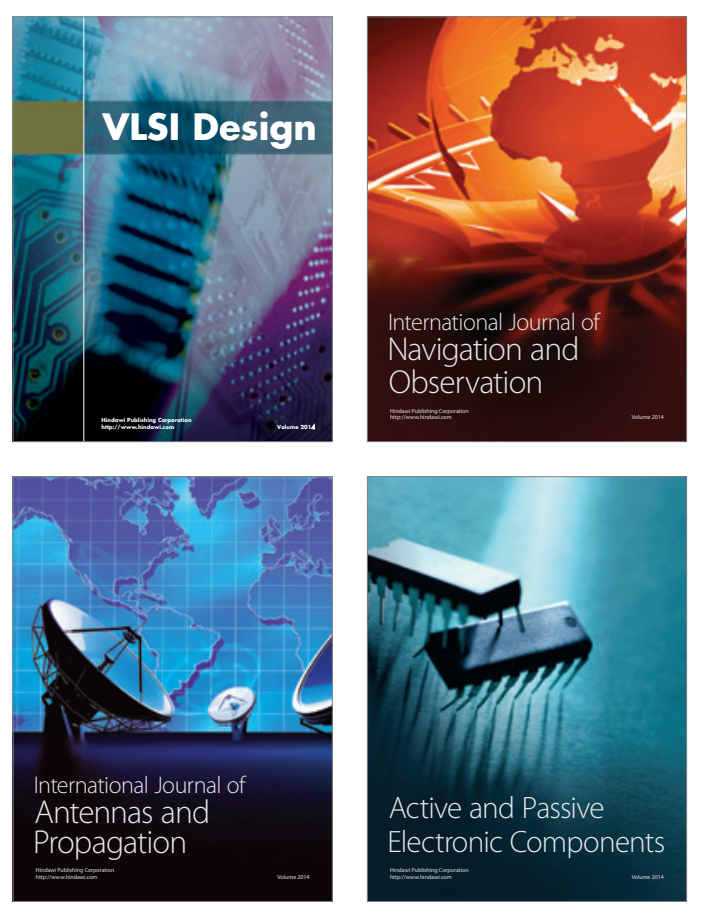
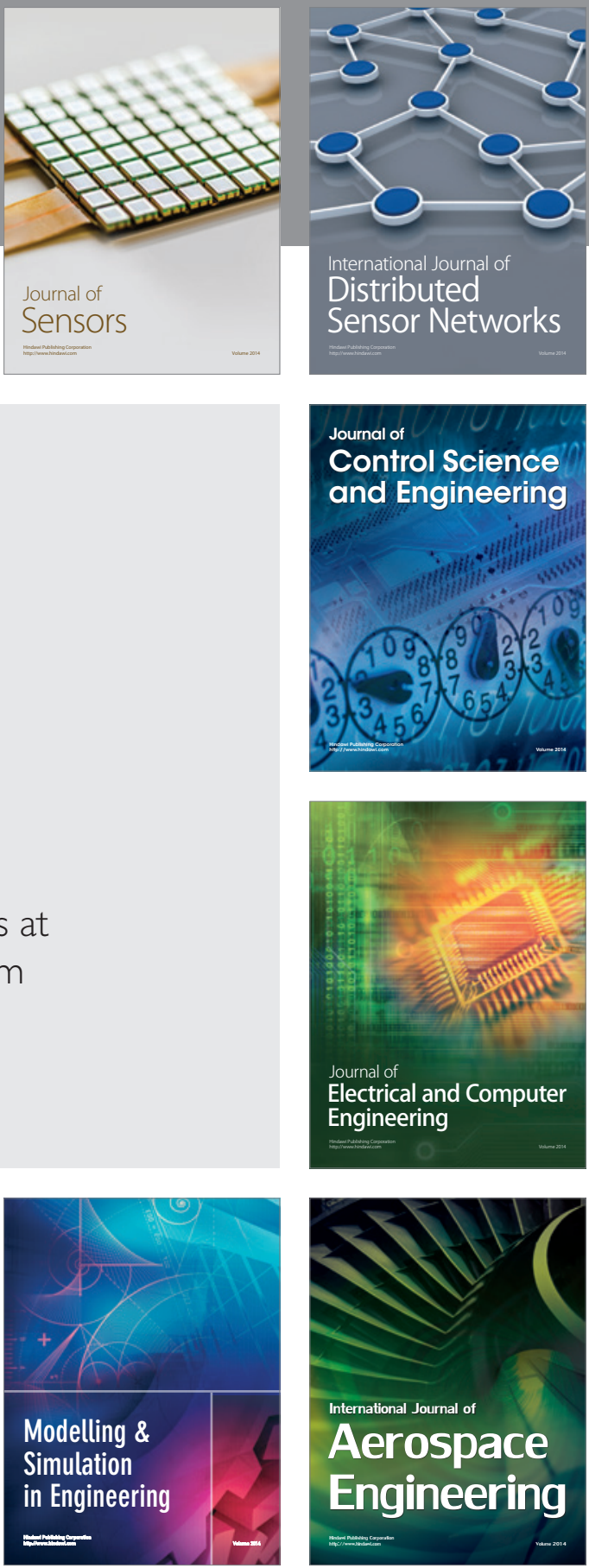

Journal of

Control Science

and Engineering
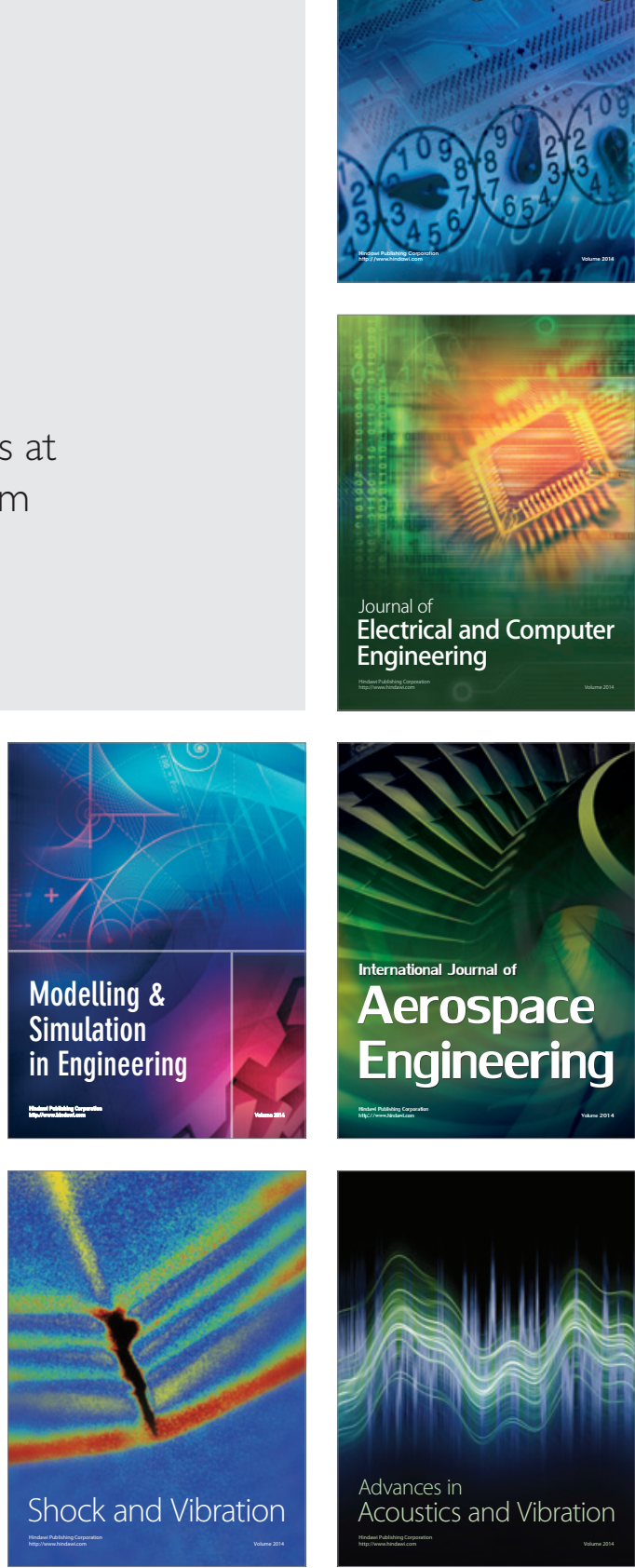